\title{
The Dilemma of Balanced Development of Preschool Education in Ethnic Minority Areas in Yunnan Province and Its Countermeasures
}

\author{
Luying Gan \\ College of Education, Yunnan Open University, Kunming, China
}

Email address

cloudstory@126.com

To cite this article:

Luying Gan. The Dilemma of Balanced Development of Preschool Education in Ethnic Minority Areas in Yunnan Province and Its Countermeasures. Science Innovation. Vol. 8, No. 5, 2020, pp. 150-154. doi: 10.11648/j.si.20200805.16

Received: October 19, 2020; Accepted: November 26, 2020; Published: November 27, 2020

\begin{abstract}
There are 25 ethnic minority areas in Yunnan Province, most of which are in remote or mountainous areas, with the influence of lagging economic development and geographical factors. the problem of preschool education in these ethnic minority areas is more prominent. As the beginning of lifelong learning, preschool education occupies an important position in the national education system. In recent years, many policies have been introduced in China, which have been effective in promoting preschool education. But it has been found that factors such as the lag in economic development level, backward parents' attitudes, overall insufficient and uneven allocation of pre-school education funds, "bilingual" teaching obstacles, and lack of teacher theory are the main bottleneck obstacles to the development of pre-school education in ethnic minority areas in Yunnan Province. This article tries to expound the bottleneck of the development of preschool education in Yunnan ethnic minority areas and make an in-depth analysis of it, according to the local conditions, it proposes feasible solutions such as setting up preschool education institutions in various forms, broadening the channels of capital investment, helping parents establish correct educational concepts, promoting the quality of bilingual teaching, strengthening the construction of teachers, promoting curriculum and teaching reform, and developing preschool education courses with national characteristics.in order to promote the balanced development of pre-school education in Yunnan ethnic areas.
\end{abstract}

Keywords: Ethnic Areas, Pre-school Education, Balanced Development, Countermeasures

\section{云南省少数民族地区学前教育均衡发展困境及其对策探究}

\section{甘露荣}

云南开放大学教育学院, 昆明, 中国

\section{邮箱}

cloudstory@126.com

摘要: 云南省有 25 个少数民族地区, 大多数处于偏远地区或者山区, 经济发展滞后以及地理因素的影响, 这些民族地 区的学前教育问题更为凸显。作为终身学习的开端, 学前教育在国民教育体系中占据重要地位。近年来, 我国出台了 诸多政策, 在学前教育工作推进上颇具成效。但经研究发现, 经济发展水平滞后、家长观念落后、学前教育经费投入 总体不足与分配不均、“双语”教学障碍、师资理论罗乏等因素仍是阻碍云南省民族地区学前教育发展的主要瓶颈障碍。 本文针对云南民族地区学前教育发展存在的问题进行深入剖析, 根据地方实际提出多形式开办学前教育机构、拓宽资 金投入渠道、帮助家长树立正确教育观念、促进双语教学质量提升、加强师资队伍建设、推进课程和教学改革, 开发 具有民族特色的学前教育课程等可行性解决措施, 以期能推动云南省民族地区学前教育均衡发展。 
关键词: 民族地区, 学前教育, 均衡发展, 对策

\section{1. 引言}

作为终身学习的开端, 学前教育在国民教育体系中占据 重要地位。近年来, 我国出台了诸多政策, 在学前教育工作 推进上颇具成效。学前教育的普及率大幅度提升、管理制度 得到完善、学前教育资源也越来越丰富, 入园困难的问题得 到有效缓解。[1]但是学前教育由于不属于义务教育范畴, 在 我国发展相对缓慢, 且发展不均衡问题严峻, 存在着管理体 系不完善、教育教学方式科学性欠缺等诸多问题。

云南省少数民族地区大多坐落于偏远山区, 经济发展 滞后以及地理因素的影响, 这些民族地区的学前教育问题 更为凸显。由于资金短缺、资源分配不均、家长观念落后 等原因, 云南民族地区学前教育发展存在着入园率低、教 育不公平等严峻问题。[2]目前相关领域学者的研究主要集 中于学前教育的发展、学前教育课程改革实践、学前教育 教师培养等, 然而针对少数民族地区学前教育相关内容研 究较少, 如何特色化办学促进民族教育均衡的研究几乎没 有。本文试图阐述云南民族地区学前教育发展的瓶颈并对 其深入剖析, 针对地方实际进一步探究可行性解决措施, 以期能为云南省民族地区学前教育均衡发展做出贡献。

\section{2. 云南省民族地区学前教育发展现状}

云南省共计 25 个少数民族, 在长期的劳动和生活中形 成了自己的语言和文化, 随着各民族的交往与融合, 教育 也在不断发展。学前教育是基础教育的重要组成部分, 其 教育成效直接影响着整个教育阶段的质量。[3]国家和政府 都越来越重视学前教育的作用, 本研究抽取云南省楚雄、 大理、西双版纳三地彝族、白族和傣族地区针对幼儿园教 师和家长进行问卷调查并向教育局相关部门访谈。有效发 放问卷639份, 从不同角度了解云南省民族地区学前教育 均衡发展相关情况。

经数据分析显示: 近年来, 云南省民族地区城、乡幼 儿入园率稳步提升; 幼儿园场地设施、幼儿教师和教育经 费投入方面都在数量上有较高幅度增长, 学前教育的办学 条件得到显著改善; 这几个民族地区学前教育师资力量主 要由中青年女性教师构成（占比 $86 \%$ ），其中 40 岁以下中 青年教师占比 $72 \%, 45 \%$ 教师为大专学历, $9 \%$ 为本科学 历，教龄在 3 年以上的教师占 $92 \%$ 。其中近 $60 \%$ 的教师接 受过专业系统教育, 且教学经验丰富。家长对所选幼儿园 的满意度调查显示 (见表1), 其中主要影响因素为幼儿 园的办学质量, 其次是师资水平、硬件设施。总的来说这 些地区学前教育质量得到提升。

表1 家长对幼儿园满意度调查描述性统计。

\begin{tabular}{llllll}
\hline & $\mathbf{N}$ & 最小值 & 最大值 & 平均数 & 标准偏差 \\
\hline 教学质量 & 950 & 0.00 & 1.00 & 0.4910 & 0.50018 \\
师资水平 & 950 & 0.00 & 1.00 & 0.4389 & 0.49652 \\
硬件设施 & 950 & 0.00 & 1.00 & 0.3969 & 0.48950 \\
有效的 $\mathrm{N}$ & 950 & & & & \\
\hline
\end{tabular}

但是回收的问卷主要是经济发展相对好的民族地区, 经过和教育局的工作人员交谈了解在较为便宜的一些山 区民族地区，由于文化和经济、地域等因素影响，教育均 衡发展受到了极大影响, 学前教育问题更为凸显。文化与 语言、资金投入不足、资源分配不均、家长观念落后等原 因导致了这些民族地区学前教育发展存在着入园率低、教 育不公平等严峻问题, 形成了学前教育均衡发展的瓶颈。

\section{3．云南省民族地区学前教育均衡发展存在的主 要困境分析}

\section{1. 经济发展水平滞后}

虽然国家出台诸多政策, 但中国的经济发展仍存在着 东西部地区发展不均衡的现象; 且城乡发展水平不均衡现 象也依然严重, 农村发展水平远远落后于城市。[4]云南省 少数民族地区大多数集中于山区及农村, 整体发展相对较 为落后。儿学前教育不是国家 9 年义务教育范畴, 因而其 发展水平受到经济发展严重制约。

\section{2. 家长观念相对落后}

学前教育是一项为家长参与生产劳动提供服务的社 会公益事业, 由于其不纳入义务教育因而不具有强制性。 在云南少数民族地区, 受传统的民俗文化、经济发展水平、 受教育程度等方面的影响, 家长对于学前教育缺乏重视, 更不理解学前教育本质、功能及存在价值。[5]多数家长不 愿意花钱将适龄子女送入专门的学前教育机构。由于家长 不正确的学前教育理念直接影响了当地学前教育的普及 与发展。据分析, 家长的主要观念主要表现如下:

\subsection{1. 学前教育无用论}

大多数民族地区家长认为学前教育机构只是老师看 着孩子, 带着孩子玩, 且需要交纳一定费用, 而家里的老 人完全能够照看。因此不愿将孩子送入专门的学前教育机 构。其次云南少数民族众多, 且很多农村民族地区民俗传 统文化观念深厚, 他们并没有接受学前教育的意愿与传统。

\subsection{2. 学前教育小学化}

许多父母注重结果, 希望孩子在学前教育机构能够学 会识字、算术、英语等知识。而这些和学前教育规律及学 前儿童心理发展规律严重不相符, 不利于小朋友身心和谐 发展。现在国家严格要求禁止学前教育小学化, 学前教育 专业机构在家长和规定之间很难做到平衡。

\section{3. 学前教育经费投入总体不足与分配不均}

教育事业发展需要稳定充足的经费作为保障, 而学前 教育事业实质上是为家长服务的国家公益事业, 其发展更 是需要国家强有力的支持。由于学前教育不在义务教育范 畴, 学前教育长期以来主要是市场资本介入, 其获得的政 
府投入只占教育经费总量的 $1.2 \%-1.3 \%$ 。[6]学前教育经 费投入是全国各类教育中最薄弱的环节, 教育经费不足是 制约学前教育均衡发展的重要因素。

近年来，国家和云南省政府虽不断出台相关政策并加 大经费投入推动民族地区学前教育发展, 但由于需求过大, 资金短缺不能满足当地学前教育发展的规模与速度, 严重 影响了教育的质量。

且对于资金的分配仍是以城市少数公办幼儿园为主, 资源分配不均使得农村民族地区学前教育发展雪上加霜。 在许多民族地区, 幼儿园的教学硬件设施缺乏, 且规模小、 场地狭窄。有的地区办不起幼儿园只有幼儿班，不同年龄 小朋友在一起进行学习。

\section{4. “双语”教学障碍}

在民族地区“双语”教学是必不可少的也是相对薄弱 的。当地许多中小学中已经普遍开展了“双语”教学, 并获 取较大成效。但是, 儿童语言发展的关键期是 3 到 7 岁, 错 过了语言学习的“关键期”, 中小学生在学习汉语的时候相 对学前儿童来说会稍显吃力, 一些地区造成了学生辍学的 结果。[7]若能在学前期掌握基本的汉语知识, 进行简单的 会话与交流, 会给民族地区小朋友未来发展带来了很多便 利和好处。

目前, 云南少数民族地区许多幼儿园已采用“双语”教 学模式, 学前教育的内容与课程主要采用当地统一使用的 教材, 而这些教材是在汉语文化和城市幼儿生活的基础上 编制的, 不符合少数民族农村地区的生活实际, 从而为当 地学前儿童的学习带来了困难。经调查发现, 云南省许多 少数民族地区民俗传统文化、语言差异与学校文化等都影 响了少数民族幼儿在幼儿园的学习与生活, 进而影响了云 南省少数民族地区学前教育发展。

\section{5. 民族地区学前教育师资力量圆乏}

云南省民族地区学前教育教师还存在相当大的缺口。 目前, 在职教师的学历层次普遍不高, 且大部分教师没有 经过专业培训, 更没有系统地学习有关学前教育的理论知 识, 缺乏基本的专业素养和能力, 难以适应现代学前教育 工作。

民族地区新引进的教师多数为中专幼师毕业, 部分还 是非学前教育专业, 本科专业毕业的几乎没有。对于优秀 人才稀缺成为阻碍民族地区学前教育发展的重要原因。[8] 首先是开设学前教育专业的学校并不多, 学生数量有限, 且许多该专业的学生未从事学前教育工作, 教师流失现象 严峻; 其次, 由于地理位置制约, 交通不变、经济落后等 现象，专业性人才不愿到这些地区就职。

\section{4. 促进云南省民族地区学前教育均衡发展的对 策及建议}

云南省少数民族地区学前教育的均衡发展关系到国 家的教育公平的发展与落实。要打破这些地区学前教育发 展的瓶颈，笔者提出以下建议措施以供参考。

\section{1. 多形式开办学前教育机构, 拓宽资金投入渠道}

\subsection{1. 学前教育机构多形式办学}

《国家中长期教育改革与发展规划纲要 （2010-2020）》在学前教育的发展任务中提出“建立政 府主导、社会参与、公办民办并举的办园体制。大力发 展公办幼儿园, 积极扶持民办幼儿园。”在短期内国家把 学前教育纳入义务教育, 并承担学前教育发展的所有经 费是不符合我国国情的。

以德国为例, 其现在的学前教育机构主要有传统幼 儿园、幼儿俱乐部、根据教育家命名的幼儿园、学校附 设的幼儿园和学前班、特殊幼儿园、托儿所、“白天的母 亲”、父母管理中心、“森林幼儿园”等。这些不同形式的 学前教育机构满足了不同社会阶层、不同文化群体学前 儿童多形式接受学前教育的需要。云南省少数民族地区 可因地制宜, 利用自己的优势和特色开设多形式的学前 教育机构。[9]

我们主要需要考虑的是经济较为落后, 资源缺乏的山 区农村地民族地区。这些地方大多拥有优越的自然环境, 处于山川景色秀美、多种植被覆盖的地区, 因地制宜, 我 们可以创办林间幼儿园。当地政府可鼓励具有专业背景的 教师开办简易的林间幼儿园, 帮助幼儿实现身心健康发展。 其次, 可利用当地小学开办学前班或者幼儿园。第三, 针 对确实没有条件开办专业性较强的学前教育机构的地区, 可利用村落里受教育程度较高的人员, 让其接受一定程度 的学前教育培训, 在本村落组建学前儿童游戏小组, 满足 学前儿童接受教育的需要。

\subsection{2. 加大政府经费保障力度}

云南省政府要跟进国家对学前教育的政策规划, 加 强政府对学前教育的管理, 充分重视学前教育的发展, 将民族地区学前教育经费投入纳入规划, 地方政府也应 增强对学前教育的扶持力度。其次, 可充分利用当地资 源, 通过改造、扩建或联合办园方式扩大学前教育机构 规模。再次, 尝试引进联系一些慈善基金会等, 请他们 来投资建园。

同时, 政府部门要加强督导管理工作, 进一步完善管 理机制, 建立专门的少数民族学前教育发展与管理机构, 由专业人员进行管理, 实行岗位责任制, 分工明确, 按照 学前教育的规律管理和发展少数民族地区学前教育事业, 规范学前教育经费的使用。[10]

\section{2. 帮助家长树立正确教育观念}

家长是孩子最重要的教师, 承担着启蒙教育的责任。 而云南少数民族贫困地区, 这些家长文化程度较低, 更不 懂学前教育。因此学校必须将帮助家长树立正确的教育观, 让其了解学前教育的意义及重要性。幼儿园应设立亲子游 园活动“开放日”, 让家长进入幼儿园与孩子一起活动, 让 家长感受儿童在学校的活动。借此机会, 幼儿园可以举办 讲座为家长传授关于学前教育的相关知识, 帮助其树立正 确的学前教育观。 
除此之外, 许多少数民族自治地区，大部分人基本使 用本民族语言。负责教师培训的相关机构应在教师的培训 中, 强调教师民族语言的培训, 扫除家长与教师的沟通障 碍。[11]同时老师需要让家长了解孩子语言发展敏感期的 规律, 支持和鼓励孩子学习普通话。

\section{3. 促进双语教学质量提升}

首先, 应创办双语幼儿园。帮助少数民族幼儿克服语 言障碍，同时也传承本民族文化。

\subsection{1. 编制适宜的学前儿童“双语”教学教材}

双语及汉语教材的建设问题成为民族教育研究的 热点。新型的双语教材应该满足教学要求, 需要全新的 编写构建理念, 明确编写宗旨、制定大纲、建立总体设 计和运用现代化技术, 这对新型教材的构建具有举足轻 重的作用。另外, 双语教材的编写还要注意少数民族的 特点, 把少数民族的语言和汉语有机地结合在一起, 注 意克服少数民族语和汉语两张皮的现象。在编写时, 学 前儿童的语言学习能力和特点也是编写教材的重要依 据。

\subsection{2. 建立合理的“双语”教学模式}

双语教学模式是介于双语教学理论与双语教学实践 之间的“中介”环节, 开展双语教学的模式研究是当前民族 双语教学论中一个综合性的课题。我们要系统化研究双语 教学过程的各种方式方法, 在理论与教学实践相结合基础 上, 构建系统化并形式多样的双语教学模式体系, 为我国 双语教学的方式方法的优选和优用提供保障。

特别是在民族地区的幼儿园里, 在进行双语教学之前 要先选择合适的双语教学模式, 这是开展双语教学很关键 的一步。在学习双语教学模式有关理论的基础上, 结合本 地区的特点、本幼儿园的特点、本民族语言的特点, 选择 适合自己地区的双语教学模式。

\subsection{3. 为少数民族儿童创造良好的学习汉语的环境}

幼儿园应该根据自己的实际情况, 为儿童创造学习汉 语、使用汉语的环境。良好的学习汉语的环境能够起到潜 移默化的影响, 使少数民族儿童在汉语的语境中学习, 这 可以使少数民族儿童经历到在具体的环境中怎样使用汉 语, 从而加速汉语的学习。

家庭与社区要积极配合幼儿园的教育, 要积极为儿童 的学习创造良好的汉语环境, 有条件的乡村和家庭应尽量 为儿童提供电视、广播、书籍、报刊等, 增加儿童接触汉 语的机会, 同时也为儿童的健康发展提供良好的条件。幼 儿园应积极营造良好的汉语环境, 如添置幼儿园广播、电 视, 订阅少儿图书、杂志等, 建立班级阅读角; 尽量鼓励 师生之间、儿童之间用普通话交流等; 定期举办讲故事比 赛等活动。

在幼儿园举行的各种学习汉语的活动中, 教师要注意 充分利用儿童有同伴交往需要的特点, 给幼儿分组, 让他 们互帮互助, 在彼此的交流中学习汉语。[12]这既能提高 幼儿汉语水平, 还能优化儿童之间的关系, 使儿童的同伴 关系得到更好的发展。

\section{4. 加强师资队伍建设}

在少数民族地区由于硬件设施不足, 学前教育质量的 提升主要依赖于教师。我们应加大师资队伍的建设, 通过 相关政策等扶持为民族地区输入优秀的教师。

\subsection{1. 政策支持}

由于少数民族地处偏远地区, 经济文化的发展相对落 后, 大学毕业生普遍不愿到少数民族地区任教以及原少数 民族地区教师出现外流现象。政府可通过提高工资、发放 补贴等, 提高幼儿教师地位等方式采取倾斜政策为民族地 区学前教育配备学前教育专业教师, 公开聘请具备条件的 大中专毕业生就职。

\subsection{2. 开展培训}

较多贫困民族地区的教师主要是当地的一些妇女, 未经过相关的专业学习, 政府应针对这些非专业教师定 期开展学前教育培训, 为他们提供学习和交流平台, 以 提高学前教育的教学质量。[13]除了学习学前教育的基本 理论和相关专业技能的训练, 还要学习民族文化、民族 语言、了解各民族生产生活情况, 以适应民族地区幼儿 的发展需求。

\subsection{3. 提升少数民族地区教师双语教学能力}

民族地区学前教师双语授课的能力水平高低对幼 儿双语教学效果起到直接影响作用。这就要求幼儿园教 师要掌握本民族的语言, 当地培养学前教育教师的师范 学院可定向招收本地区不同少数民族的学生, 为当地少 数民族培养专门的学前教育师资。[14]其次, 很多地区 教师的汉语水平、专业水平并不能胜任双语教学。因此, 在少数民族地区应该发挥县教师教育、培训机构的作用 以及多媒体远距离教学的作用, 加强师资培养培训, 提 高教师的整体素质。

\section{5. 推进课程和教学改革, 开发具有民族特色的学前教 育课程}

我国的课程管理体系分为三级，即国家课程、地方课 程以及校本课程。各地方、幼儿园可以根据当地实际及特 色开发校本课程。云南少数民族地区学前教育理念落后, 更应加大课程及教学改革的力度, 开发具有民族地区特色 的学前教育课程。目前一些民族地区的主要是引进的汉族 教材, 和当地的民俗文化、生活方式等都有较大的差异, 教材脱离了儿童的生活实际。[15]对于民族地区地方课程 要结合地方经济特征传授贴近乡土的知识和技能, 整合和 利用地方资源。

在课程开发时应争取当地高校专家支持, 并由当 地谙熟地方民俗民情的教师配合, 致力于开发具有本 民族、本地区特色的园本课程; 其次, 针对少数民族 地区幼儿园硬件设施缺乏等困境, 我们可充分运用地 理自然环境优势, 选择与当地学前儿童生活紧密联系 又是学前儿童生活中最需要同时对学前儿童长远发展 具有价值的内容作为课程开发的重点。如开发田园观 察植物的生长过程的课程、树林里学数学的课程、小 
溪边去观察风车来了解力的课程等。具有少数民族农 村特色的校本课程能有效促进学前儿童对本民族文化 的认同，使民族文化得到传承与发扬。这也为民族凝 聚力的增强奠定了基础。

\section{5. 结论}

云南省在促进民族地区学前教育均衡发展过程中不 断探索尝试并获得了较大成效, 但发展过程中仍存在一些 问题及困境待解决。我们可立足于云南的地域性和民族教 育的民族性，结合云南民族地区的民族文化，通过多形式 开办学前教育机构, 拓宽资金投入渠道; 帮助家长树立正 确教育观念; 促进双语教学质量提升; 加强师资队伍建设; 推进课程和教学改革, 开发具有民族特色的学前教育课程 等可行性措施来推动云南省民族地区学前教育均衡发展, 以期为云南省民族教育水平提升以及增进民族团结做出 贡献。

\section{致谢}

此论文完成之际, 首先向课题组（云南省教育厅科研 基金资助项目《“互联网+教育”背景下推进云南省民族教 育均衡发展探索研究》 (项目编号: 2018JS374)) 所有 成员表示最衷心感谢和最诚挚的敬意。各位老师在调研和 后期数据分析时给予我很大帮助。衰心感谢所有关心和帮 助我的人, 在大家共同努力下该项目研究工作才能顺利推 进, 谢谢你们。

本文为云南省教育厅科研基金资助项目《“互联网+ 教育”背景下推进云南省民族教育均衡发展探索研究》(项 目编号：2018JS374）的阶段性成果之一。

\section{参考文献}

[1] 屈艳娜.当前我国学前教育面临的主要问题与挑战[J].才智, 2016(33)。
[2] 㶓国书.云南民族地区学前教育发展现状与对策研究— 以西双版纳州为例 $[J]$.学园:教育科研, 2012(19):40-42。

[3] 刘晓红.我国农村学前教育发展中的间题、困难及其发展路 向[J].学前教育研究, 2012(3):32。

[4] 陈爱华,秦旭芳.督导视角下县域学前教育发展探究:瓶颈与 突破 [J].教育探究, 2016(02)。

[5] 童欢,侯再宣.西部农村学前教育发展的现实困境及对策研 究——以贵州和甘肃两省为例 [J]. 铜仁职业技术学院学术 论坛, 2016(01)。

[6] 邓红红.浅析社区学前教育发展的困境及应对策略[J].黑龙 江教育学院学报,2010(06)。

[7] 陈娟娟,孙瑜,田莉等.民族教育信息资源数字化现状分析与 归因、对策的研究 [J].中国电化教育, 2013（7）。

[8] 段从宇,甘建侯. 适应、引领与超越:云南民族教育信息化建 设研究[J].学术探索, 2015（1）。

[9] 余宇,单大圣.中国学前教育发展70年及未来展望[J].发展研 究,2019(10)。

[10] 张建群.影响农村学前教育发展的因素及对策研究——基 于对康乐、榆中等地农村学前教育发展的调查 $[\mathrm{J}]$. 教育革 新,2011(05)。

[11] 王轶, 石纬林, 崔艳辉. “互联网+”时代青年教师信息素养 研究 $[\mathrm{J}]$.中国电化教育, 2017（3）。

[12] 梁林梅,陈圣日,许波.以城乡同步互动课堂促进山区农村学 校资源共享的个案研究——以“视像中国”项目为例 [J].电 化教育研究,2017,38（3）:35-40。

[13] 权迎. 民族地区卓越幼儿教师培养机制研究一以云南 $\mathrm{K}$ 校 为例 $[\mathrm{J}]$.荆楚学刊, 2017(05)。

[14] 江全.民族化双语化专业化合作化一一民族地区学前教育 新师资培养导向[J].唐山师范学院报,2013(01)。

[15] 冯江英,石路.近十年新疆学前双语教育基本公共服务体制 改革与政策演进[J].双语教育研究, 2017(01)。 